\title{
Asthma control in the workplace
}

\author{
Louis-Philippe Boulet
}

Affiliations: Institut de cardiologie et de pneumologie de Québec, Laval University, Quebec, QC, Canada.

Correspondence: L-P. Boulet, Institut universitaire de cardiologie et de pneumologie de Québec, 2725, Chemin Sainte-Foy, Québec, QC, G1V 4G5 Canada. E-mail: Ipboulet@med.ulaval.ca

0

@ERSpublications

Cleaning agents pose particular difficulties for the control of workplace-related asthma symptoms http://ow.ly/q3gsr

Workplace exposures may result, in susceptible workers, in the development of occupational asthma from sensitising or toxic/irritant exposure, or in the worsening of a pre-existing asthmatic condition, so-called "work-exacerbated asthma" [1-3]. Occupational asthma is a relatively common condition, although it is often unrecognised $[1,4]$. Exposure to the sensitising agents can lead to permanent airway changes, so that even when stopped, the majority of workers will still experience persistent asthma symptoms and show residual airway hyperresponsiveness [2-5]. Early cessation from exposure to the offending agent, however, results in a better prognosis, while persistent exposure can lead to more severe asthma and more frequent acute asthma events $[5,6]$.

It has become evident from recent studies of work-exacerbated asthma that exposure to "asthmagens" and irritants at the workplace can lead to troublesome symptoms and trigger exacerbations of asthma $[1,6,7]$. As for non-work-related asthma, poor asthma control can result from common environmental exposures, such as allergens or pollutants in susceptible subjects, or from insufficient controller therapy or nonadherence to it. Such poor "baseline" airway control may render the worker more susceptible to the effects of various dusts, aerosols and other contaminants at work, and predispose to asthma exacerbations $[1,8,9]$. However, the contribution of various exposures at work to asthma control and exacerbations remains to be better documented.

The European Community Respiratory Health Survey (ECRHS) I and II have been a rather useful source of information on asthma and these data are certainly still currently relevant. In this issue of the European Respiratory Journal, Le MouAl et al. [10] looked at the relationship between occupational exposures and asthma control, as defined by the Global Initiative for Asthma criteria, in workers who took part in ECRHS II. Out of the 7077 participants (mean age 43 years, 45\% never-smokers) 1210 were considered to have current asthma. After controlling for other potential factors, including exposure to common airborne allergens, significant positive associations were observed between uncontrolled adult-onset asthma (mainly the exacerbation domain) both for the previous 12-month and 10-year exposure, and occupational "asthmagens". These last included both high and low molecular weight agents, particularly cleaning agents, and a time duration of exposure effect was noted. Regional differences were observed, probably due to variable degrees of exposure or other factors. Interestingly, there was no effect of smoking or obesity on the relationship. The authors suggest that occupational exposure to asthmagens is associated with uncontrolled asthma and that occupational risk factors should be quickly identified to address this lack of control.

These results are in accordance with previous observations from ECRHS II that occupational exposure to occupational agents is associated with severe asthma exacerbations [11]. In the present study, such associations were stronger for the previous 10-year than 12-month occupational exposures for adult-onset uncontrolled asthma [10], in keeping with a previous report [12]. This poorer asthma control with prolonged exposure may result from the development of a more severe form of asthma, as suggested in a

Received: Aug 072013 | Accepted: Aug 082013

Conflict of interest: Disclosures can be found alongside the online version of this article at www.erj.ersjournals.com

Copyright (CERS 2014 
previous analysis of the Epidemiological Study on the Genetics and Environment of Asthma (EGEA) cohort [13]. The increased use of inhaled and oral corticosteroids in the uncontrolled asthma group from the study conducted by Le Moual et al. [10] is in keeping with this possibility, and suggests that these workers may have stayed at work at the expense of increased use of these agents, although even in that case, asthma remained still poorly controlled.

The observation of poorer asthma control with prolonged exposure to asthmagens, even in non-sensitised workers, may also be related to the long-term effects of such occupational exposures on the asthma phenotype. In this regard, we previously showed the various inflammatory phenotypes of occupational asthma according to the type of offending agent, and also that independently of the diagnosis of occupational or work-exacerbated asthma, a neutrophilic phenotype was associated with poorer asthma control and a longer duration of exposure than eosinophilic or paucigranulocytopenic asthma [7, 14]. Furthermore, we showed that workers with work-exacerbated asthma seemed, surprisingly, to even have an increased asthma severity compared to workers with occupational asthma, in addition to having a more noneosinophilic asthma phenotype [7]. In this last study, both workers with occupational or workexacerbated asthma had greater health care use and a 10-fold higher direct care costs than non-work-related asthma. The more troublesome asthma in workers with work-exacerbated asthma may be due in part to the fact that some of those with occupational asthma may have left work, creating the healthy worker effect $[7,15]$. Nevertheless, the above studies stress the need to better evaluate the effects of environmental workplace exposures on asthma control, even in non-sensitised workers, as they can lead to more severe and troublesome asthma in both groups.

We can suppose that the poor asthma control and more frequent exacerbations in workers with occupational asthma (although this was not formally diagnosed in the present survey) is due to sensitiser exposure-related increases in airway inflammation, probably on top of progressively increasing airway remodelling [7, 14, 16, 17]. For work-exacerbated asthma, this is still unclear. In workers with workexacerbated asthma, laboratory exposure to occupational agents did not increase airway inflammation, although a long-term change in asthma phenotype (becoming more neutrophilic) is still possible, as shown for smokers $[18,19]$. Airway sensory nerve activation could also be involved in the response to triggers, as suggested in animal models for smoke or chlorine gases [20]. Progressive asthmagen/irritant-induced changes in airway structure may also be involved in the increasingly troublesome asthma observed in workers. As an example for other types of exposure to air pollutants, we previously hypothesised that longterm exposure to chlorine derivatives could contribute to airway remodelling in high-level swimming athletes, through an effect on airway epithelium [21]. A possible "mechanical" induction of remodelling from repeated bronchoconstriction induced by workplace inhalants is also possible, although less likely [22].

Another intriguing observation in the study reported by LE Moual et al. [10] is the lack of association between asthmagen exposure and partly controlled asthma, as previously reported [10, 23]. This may be explained by the fact that it mostly involved exacerbations, which also suggests a stronger effect of this type of exposure on asthma control and/or an increased delay in reporting symptoms, with workers preferring staying at work rather than consulting a physician, and raising the possibility of being asked to consider to another type of work.

Prevention of exacerbations is an important goal in asthma management, as stressed by all recent guidelines, as they may result in an accelerated decline in lung function, reduced quality of life and increased socioeconomic burden of disease [7, 11, 24, 25]. Search for contributing and causal factors in the uncontrolled asthmatic patient should, therefore, not only include respiratory infections, common airborne allergen exposures and other factors, such as non-adherence to therapy, but workplace exposures should also be carefully documented. In this regard, the report from LE MOUAL et al. [10] further stresses the role of occupational exposures on exacerbations. Interestingly, such influence of the workplace on asthma control seems particularly important for cleaning agents [14, 26-28]. This category of agents has been responsible for both new-onset occupational asthma, from sensitisation or "toxic" exposures (irritant-induced asthma/ reactive airway dysfunction syndrome), as well as for work-exacerbated asthma episodes. Such effect on asthma control does not probably only result from the sensitising properties of some of these agents, but also from the strong irritant effects in the airways of many of them, particularly some low molecular weight agents, such as some cleaning agents, although this needs further documentation [27].

In conclusion, this analysis deals with another important set of data obtained from the large ECRHS database, and brings additional information on the effects of the workplace environment on asthma control. Low molecular weight agents and, more specifically, cleaning agents, even in non-sensitised patients, seem particularly associated with poor asthma control, mainly for its criteria of "asthma exacerbations". These data further stress the sometimes difficult task of the clinician, to carefully document the role of workplace exposure in uncontrolled asthma. As cessation of exposure is a key measure in sensitised workers with a 
diagnosis of occupational asthma, and with all resulting socio-economic consequences in some workers, it may be necessary to refer to a specialised centre for confirmation of such a diagnosis whenever suspected. In work-exacerbated asthma, various measures to minimise the untoward effects of workplace exposures may help, such as good quality face masks, sufficient preventative medication and relevant industrial hygiene measures, while closely monitoring asthma control. However, these measures may be difficult to apply or may be insufficient, and the clinician may have to suggest that the worker move to another type of work, particularly if asthma is difficult to control and/or is associated with frequent work-related exacerbations.

\section{References}

1 Tarlo SM, Malo JL. Third Jack Pepys Workshop on Asthma in the Workplace Participants. An official ATS proceedings: asthma in the workplace: the Third Jack Pepys Workshop on Asthma in the Workplace: answered and unanswered questions. Proc Am Thorac Soc 2009; 6: 339-349.

2 Sastre J, Vandenplas O, Park HS. Pathogenesis of occupational asthma. Eur Respir J 2003; 22: 364-373.

3 Malo JL, Vandenplas O. Definitions and classification of work-related asthma. Immunol Allergy Clin North Am 2011; 31: 645-662.

4 Cullinan P, Cannon J. Occupational asthma often goes unrecognised. Practitioner 2012; 256: 15-18.

5 Vandenplas O, Dressel H, Wilken D, et al. Management of occupational asthma: cessation or reduction of exposure? A systematic review of available evidence. Eur Respir J 2011; 38: 804-811.

6 Malo JL. Asthma may be more severe if it is work-related. Am J Respir Crit Care Med 2005; 172: 406-407.

7 Lemière C, Boulet LP, Chaboillez S, et al. Work-exacerbated asthma and occupational asthma: do they really differ? J Allergy Clin Immunol 2013; 131: 704-710.

8 Wark PA, Gibson PG. Asthma exacerbations. 3: Pathogenesis. Thorax 2006; 61: 909-915.

9 Torén K, Brisman J, Olin AC, et al. Asthma on the job: work-related factors in new-onset asthma and in exacerbations of pre-existing asthma. Respir Med 2000; 94: 529-535.

10 Le Moual N, Carsin A-E, Siroux V, et al. Occupational exposures and uncontrolled adult-onset asthma in the European Community Respiratory Health Survey II. Eur Respir J 2014; 43: 374-386.

11 Henneberger PK, Mirabelli MC, Kogevinas M, et al. The occupational contribution to severe exacerbation of asthma. Eur Respir J 2010; 36: 743-750.

12 Jacquemin B, Kauffmann F, Pin I, et al. Air pollution and asthma control in the Epidemiological study on the Genetics and Environment of Asthma. J Epidemiol Community Health 2012; 66: 796-802.

13 Le Moual N, Siroux V, Pin I, et al. Asthma severity and exposure to occupational asthmogens. Am J Respir Crit Care Med 2005; 172: 440-445.

14 Prince $\mathrm{P}$, Lemière C, Dufour MH, et al. Airway inflammatory responses following exposure to occupational agents. Chest 2012; 141: 1522-1527.

15 Le Moual N, Kauffmann F, Eisen EA, et al. The healthy worker effect in asthma: work may cause asthma, but asthma may also influence work. Am J Respir Crit Care Med 2008; 177: 4-10.

16 Boulet LP, Laviolette M, Turcotte $\mathrm{H}$, et al. Bronchial subepithelial fibrosis correlates with airway responsiveness to methacholine. Chest 1997; 112: 45-52.

17 Bergeron C, Boulet LP. Structural changes in airway diseases: characteristics, mechanisms, consequences, and pharmacologic modulation. Chest 2006; 129: 1068-1087.

18 Lemière C, Chaboillez S, Malo JL, et al. Changes in sputum cell counts after exposure to occupational agents: what do they mean? J Allergy Clin Immunol 2001; 107: 1063-1068.

19 Polosa R, Thomson NC. Smoking and asthma: dangerous liaisons. Eur Respir J 2013; 41: 716-726.

20 Henneberger PK, Redlich CA, Callahan DB, et al. An official American Thoracic Society statement: workexacerbated asthma. Am J Respir Crit Care Med 2011; 184: 368-378.

21 Bougault V, Turmel J, St Laurent J, et al. Asthma, airway inflammation and epithelial damage in swimmers and cold-air athletes. Eur Respir J 2009; 33: 740-746.

22 Tschumperlin DJ, Drazen JM. Chronic effects of mechanical force on airways. Annu Rev Physiol 2006; 68: 563-583.

23 Siroux V, Boudier A, Bousquet J, et al. Asthma control assessed in the EGEA epidemiological survey and healthrelated quality of life. Respir Med 2012; 106: 820-828.

24 Lemiere C, Forget A, Dufour MH, et al. Characteristics and medical resource use of asthmatic subjects with and without work-related asthma. J Allergy Clin Immunol 2007; 120: 1354-1359.

25 Baur X, Sigsgaard T, Aasen TB, et al. Guidelines for the management of work-related asthma. Eur Respir J 2012; 39: 529-545.

26 Le Moual N, Varraso R, Siroux V, et al. Domestic use of cleaning sprays and asthma activity in females. Eur Respir J 2012; 40: 1381-1389.

27 Quirce S, Barranco P. Cleaning agents and asthma. J Investig Allergol Clin Immunol 2010; 20: 542-550.

28 Boulet LP. Increases in airway responsiveness following acute exposure to respiratory irritants. Reactive airway dysfunction syndrome or occupational asthma? Chest 1988; 94: 476-481. 